\title{
Tissue characterization with native T1 mapping in suspected coronary microvascular dysfunction and no obstructive coronary artery disease: results from the NHLBI-sponsored WISE study
}

\author{
Jaime L Shaw ${ }^{1,2}$, Michael D Nelson ${ }^{3}$, Janet Wei ${ }^{3}$, Puja K Mehta ${ }^{3}$, Louise E Thomson ${ }^{3}$, Daniel S Berman ${ }^{1}$,
} Debiao Li $\mathrm{il}^{1,2}, \mathrm{C}$ Noel Bairey Merz ${ }^{3}$, Behzad Sharif ${ }^{* *}$

From 19th Annual SCMR Scientific Sessions

Los Angeles, CA, USA. 27-30 January 2016

\section{Background}

About half of all women who present with symptoms of ischemic heart disease have no obstructive coronary artery disease. These women are often deemed "low-risk" patients according to conventional cardiology wisdom. The Women's Ischemia Syndrome Evaluation (WISE) studies have demonstrated suspected coronary microvascular dysfunction (CMD) in women with persistent angina, evidence of ischemia by stress test and no obstructive coronary artery disease (CAD), defined as $>50 \%$ stenosis. Women with suspected CMD also carry a higher risk of major adverse cardiac events including heart failure (HF). It is also known that diffuse myocardial fibrosis and reduced diastolic function are features in HF. The physiological mechanism behind increased HF in suspected CMD is not known. We assessed the hypothesis that function would be reduced along with previously shown elevated native myocardial $\mathrm{T} 1$ in suspected CMD.

\begin{abstract}
Methods
We evaluated the presence of diffuse fibrosis in women with suspected CMD and healthy controls using native T1 mapping at $1.5 \mathrm{~T}$ (Siemens Avanto) with a 5(3)3 MOLLI sequence in a single mid-ventricular slice. Functional imaging included short-axis cine images analyzed with feature-tracking software to determine strain and strain rate (cvi42, Circle Cardiovascular Inc.). Suspected CMD subjects had persistent symptoms of angina, evidence of
\end{abstract}

Biomedical Imaging Research Institute, Cedars-Sinai Medical Center, Los Angeles, CA, USA

Full list of author information is available at the end of the article ischemia on stress testing, and no obstructive CAD. Healthy controls had no history of cardiovascular disease and a normal exercise treadmill test.

\section{Results}

Reference control women $(\mathrm{n}=11)$ and women with suspected CMD $(\mathrm{n}=28)$ were well matched in age $(50.5 \pm$ 10.4 vs $53.1 \pm 12.3, \mathrm{p}=0.53)$, body mass index $(25.9 \pm 4.5$ vs $25.1 \pm 5.3, \mathrm{p}=0.64)$, and preserved left ventricular ejection fraction $(64.5 \pm 2.8$ vs $61.9 \pm 8.4, \mathrm{p}=0.33)$. We found elevated native T1 values in women with suspected CMD compared to control women $(1034.4 \pm 32.4$ vs $1003.2 \pm$ $19.3 \mathrm{~ms}, \mathrm{p}<0.01)$. In subjects with suspected CMD no association was observed between native $\mathrm{T} 1$ and age, body mass index, hypertension, Myocardial Perfusion Reserve Index (MPRI, a non-invasive measure of coronary flow reserve), or presence of late gadolinium enhancement. A negative association between native $\mathrm{T} 1$ and left ventricular ejection fraction was demonstrated $(\mathrm{r}=-0.423, \mathrm{p}=0.03)$. Diastolic circumferential strain rate was impaired in women with suspected CMD compared to controls with a trend towards significance $(106.1 \pm 26$ vs $126.2 \pm 37 \% / \mathrm{s}$, $\mathrm{p}=0.068$ ), consistent with and expanding previous work with tissue tagging in women with suspected CMD.

\section{Conclusions}

Among women with suspected CMD, native myocardial $\mathrm{T} 1$ is elevated compared to controls consistent with diffuse fibrosis. The trend towards impaired diastolic circumferential strain rate along with significantly elevated native $\mathrm{T} 1$ indicate a possible link of fibrosis and reduced diastolic function in subjects with CMD. Our results further 


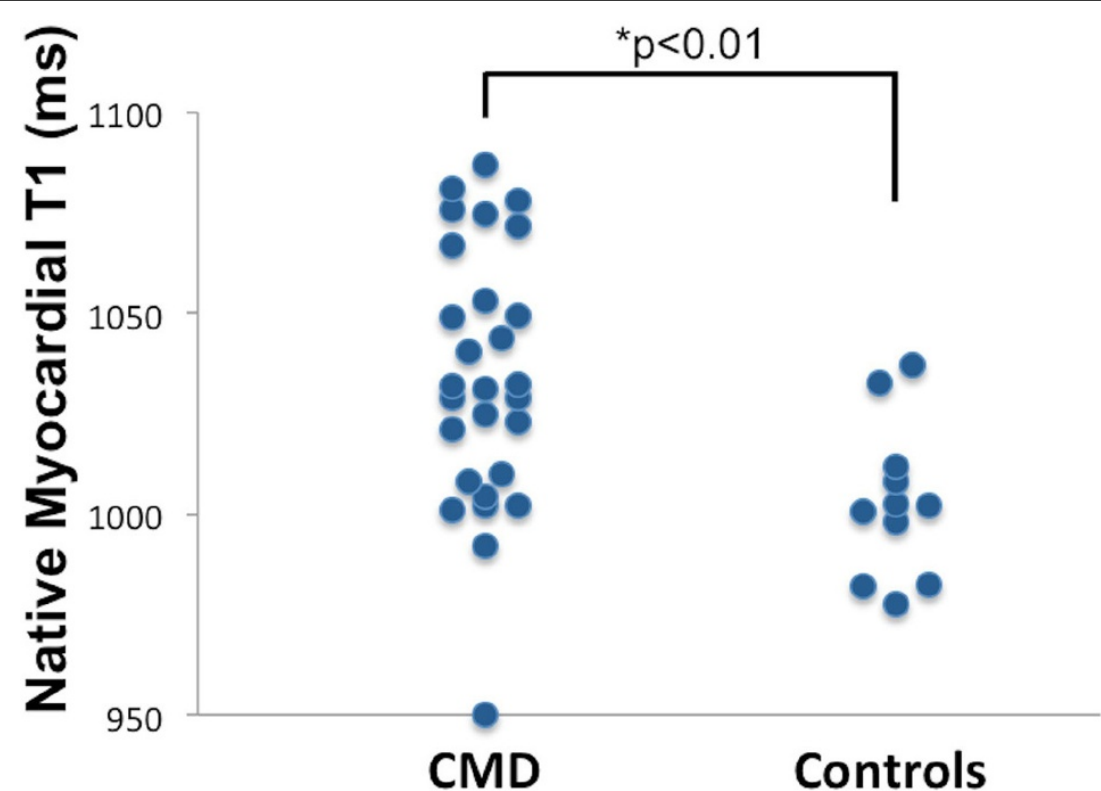

Figure 1 Native myocardial T1 in subjects with suspected CMD versus healthy controls $(1034.4 \pm 32.4$ vs $1003.2 \pm 19.3 \mathrm{~ms}$, $\mathrm{p}<0.01)$.

expand on previous work in CMD and may help to elucidate the potential underlying mechanism leading to $\mathrm{HF}$ and other adverse events in CMD.

\section{Authors' details}

'Biomedical Imaging Research Institute, Cedars-Sinai Medical Center, Los Angeles, CA, USA. ${ }^{2}$ Bioengineering, UCLA, Los Angeles, CA, USA. ${ }^{3}$ Barbra Streisand Women's Heart Center, Cedars-Sinai Heart Institute, Los Angeles, CA, USA.

Published: 27 January 2016

doi:10.1186/1532-429X-18-S1-043

Cite this article as: Shaw et al:: Tissue characterization with native T1 mapping in suspected coronary microvascular dysfunction and no obstructive coronary artery disease: results from the NHLBI-sponsored WISE study. Journal of Cardiovascular Magnetic Resonance 2016

18(Suppl 1):O43.

Submit your next manuscript to BioMed Central and take full advantage of:

- Convenient online submission

- Thorough peer review

- No space constraints or color figure charges

- Immediate publication on acceptance

- Inclusion in PubMed, CAS, Scopus and Google Scholar

- Research which is freely available for redistribution

Submit your manuscript at www.biomedcentral.com/submit 